\title{
Effects of cinnamaldehyde and thymol on cytotoxicity, tight junction barrier resistance, and cyclooxygenase- 1 and -2 expression in Caco-2 cells
}

\author{
H. Putaala ${ }^{1,2}$, P. Nurminen ${ }^{1}$ and K. Tiihonen ${ }^{1}$ \\ ${ }^{1}$ DuPont Nutrition and Health, Global Health and Nutrition Science, 02460 Kantvik, Finland
}

KEY WORDS: essential oils, feed,

Caco-2, permeability, lactate dehydrogenase, proliferation

Received: 29 December 2015

Revised: 20 June 2017

Accepted: 11 September 2017

${ }^{2}$ Corresponding author:

e-mail: heli.putaala@dupont.com

\begin{abstract}
Cinnamaldehyde and thymol are essential oils that are used as alternatives to antimicrobials in animal feed. The aim of the study was to examine the effects of cinnamaldehyde and thymol separately and in combination at amounts used in animal feed $\left(5 \mathrm{mg} \cdot \mathrm{kg}^{-1}\right.$ cinnamaldehyde and $15 \mathrm{mg} \cdot \mathrm{kg}^{-1}$ thymol) on cell membrane permeability, cell proliferation, tight junction integrity and cyclooxygenase-1 and -2 (COX1 and COX2, respectively) gene expression in the Caco-2 line, an intestinal epithelial cell model. Individually, thymol and cinnamaldehyde at below $50 \mathrm{mg} \cdot \mathrm{I}^{-1}$ or $100 \mathrm{mg} \cdot \mathrm{I}^{-1}$ in cell culture medium exerted negligible effects on cell membrane permeabilization and proliferation. Thymol increased tight junction integrity by max. $61.7 \pm 5.4 \%$ at $100 \mathrm{mg} \cdot \mathrm{ml}^{-1}$, whereas cinnamaldehyde weakened it by $\max .76 .8 \pm 0.3 \%$ at $100 \mathrm{mg} \cdot \mathrm{I}^{-1}$. However, when the essential oils were combined together, tight junction integrity rose by $49.7 \pm 4.4 \%$, and no weakening effect of cinnamaldehyde was evident. Thymol up-regulated COX1 transcription and increased the COX1:COX2 ratio, which has been suggested to be beneficial for intestinal health. Treatment with combined essential oils for $48 \mathrm{~h}$ altered 33 genes expression by microarray analysis, with no enrichment in any gene ontology class. The combination of cinnamaldehyde and thymol did not affect membrane permeability or cell proliferation in intestinal epithelial cells. In contrast, it had beneficial effects on tight junction integrity. Thus, the combination of such essential oils as cinnamaldehyde and thymol at the amounts that are used in feed is not cytotoxic to Caco-2 cells, an intestinal epithelial cell model.
\end{abstract}

\section{Introduction}

Essential oils (EOs) are plant-produced aromatic metabolites that are widely used in the pharmaceutical, sanitary, cosmetic, agricultural and food industries because of their antioxidant properties, which preserve foods from the toxic effects of oxidants (Bakkali et al., 2008), and their ability to inhibit the growth of various pathogens (Reichling et al., 2009). EOs have also garnered interest in farming as an alternative to antibiotics due to their antimicrobial activities (Amerah and Ouwehand, 2016).

Thymol (2-isopropyl-5-methylphenol) is a natural monoterpene phenol derivative of cymene and a major component of thyme oil. Cinnamaldehyde (3-phenyl-2-propenal) is an aromatic aldehyde and a principal constituent of cinnamon bark EO. These two oils improve broiler performance and gut microbiota, especially in the caecum, by lowering the proportion of Escherichia coli (Tiihonen et al., 2010). 
Generally, EOs are lipophilic and can penetrate cell wall and cytoplasmic membranes, affecting their permeabilization and depolarization (Reichling et al., 2009). EOs can interact with cellular metabolism pathways and induce apoptosis (Reichling et al., 2009). However, the potential for and degree of cytotoxicity induction differ between EOs, which are usually non-genotoxic (Bakkali et al., 2008).

The intestinal epithelium constantly encounters foreign antigens. One mechanism of controlling their passage across the intestinal epithelium is the presence of the tight junctions (TJs) as dynamic seals between adjacent cells (Ulluwishewa et al., 2011). Various vegetable extracts can decrease or improve intestinal epithelial permeability, depending on the source (Ulluwishewa et al., 2011).

Cyclooxygenase-1 and -2 (COX-1 and 2, respectively; encoded by $C O X 1$ and $C O X 2$ genes, respectively), also known as prostaglandin-endoperoxide synthase 1 and 2 (PTGS1 and PTGS2), are enzymes that synthesize prostaglandins from arachidonic acid. Prostaglandins mediate proinflammatory responses but also increase mucous secretion and gastric mucosal blood flow (Simmons et al., 2004). The two enzyme isoforms differ with regard to their mode of action. COX-1 is a constitutive enzyme that has homeostatic functions in adult and foetal gastrointestinal tract (GIT) (Burdan et al., 2008). In contrast, COX-2 is induced during inflammatory reactions and under pathological conditions, such as cancer (Simmons et al., 2004). The effects of cinnamaldehyde and thymol on COX activity and protein expression have been widely studied (e.g., Marsik et al., 2005), but the impact of their combination has never been evaluated before.

In this study, the effects of cinnamaldehyde, thymol and their combination on markers of cellular cytotoxicity were examined by measuring membrane permeabilization by lactate dehydrogenase (LDH) assay and cellular proliferation by WST-1 assay in an intestinal epithelial cell line, Caco-2 cells. Cinnamaldehyde and thymol were chosen since they have antimicrobial properties (Amerah and Ouwehand, 2016). Differentiated Caco-2 cells which are model of intestinal epithelial cells were used to determine whether the examined EOs affect TJ integrity. The cinnamaldehyde and thymol ability to alter the $C O X 1$ and $C O X 2$ genes expression in Caco-2 cells in comparison with enterohaemorrhagic $E$. coli (EHEC) was also studied. The long-term effects of the combination of cinnamaldehyde and thymol on the regulation of gene expression using Affymetrix chips were also assessed.

\section{Material and methods}

\section{Caco-2 cell culture}

Caco- 2 cells (ECACC, Health Protection Agency Culture Collections, Salisbury, UK) were maintained at $37{ }^{\circ} \mathrm{C}$ in $5 \% \mathrm{CO}_{2}$ atmosphere (Heracell 150i, Thermo Fisher Scientific, Waltham, MA, USA) in Dulbecco's modified Eagle's medium (DMEM) with high glucose and glutamine content supplemented with $10 \%$ foetal bovine serum (FBS), $1 \mathrm{X}$ nonessential amino acids, $1 \mathrm{mM}$ sodium pyruvate, $20 \mathrm{U} \cdot \mathrm{ml}^{-1}$ penicillin, $20 \mu \mathrm{g} \cdot \mathrm{ml}^{-1}$ streptomycin and $0.5 \mu \mathrm{g} \cdot \mathrm{ml}^{-1}$ amphotericin (Thermo Fisher Scientific, Waltham, MA, USA). Caco-2 cells from a different source (ATCC, LGC Standards, Boras, Sweden) were maintained at $37{ }^{\circ} \mathrm{C}$ in $5 \% \mathrm{CO}_{2}$ atmosphere with $95 \%$ humidity (Heracell 150i, Thermo Fisher Scientific, Waltham, MA, USA) in similar medium as the cells from ECACC but with 20\% FBS addition, growing better at this higher percentage of serum.

The medium during culturing was changed twice per week until the cells reached approximately $80 \%$ confluence. Then, they were detached from the plastic surfaces of the culture bottles using TrypLETM Express without phenol red (Thermo Fisher Scientific, Waltham, MA, USA). The cells were collected in $50 \mathrm{ml}$ conical tubes with $5 \mathrm{ml}$ serum, centrifuged at $179 \mathrm{~g}$ for $5 \mathrm{~min}$ at room temperature (Megafuge 1.0, Thermo Fisher Scientific, Waltham, MA, USA), washed with phosphate-buffered saline ( $\mathrm{pH}$ 7.2; Thermo Fisher Scientific, Waltham, MA, USA) and recentrifuged. The cell pellet was suspended in the growth medium and diluted. The cells from ATCC were diluted 1:4, and those from ECACC were diluted 1:6. The cells were then replated in plastic culture flasks (Greiner Bio-One Ltd., Gloucestershire, UK) for maintenance and growth.

The cells from ATCC were used in experiments on differentiated cells at passages P30-P35, whereas those from ECACC were used in experiments that measured LDH and WST-1 at passages P48-P58. Two sources of cells were used, because more robust differentiation was obtained with cells from ATCC, as measured using transepithelial electrical resistance (TEER) (data not shown). The cells from ECACC were of higher passages, which has been shown to affect TEER values (Hughes et al., 2007).

\section{Lactate dehydrogenase (LDH) release and proliferation assays (WST-1)}

For LDH assay, Caco-2 cells (250 000 cells, P48, ECACC) were seeded in 24-well plates (Greiner Bio-One Ltd., Gloucestershire, UK) and incubated 
overnight in growth medium, then they were incubated for another $24 \mathrm{~h}$ in growth medium without FBS or antibiotics. The experiment was conducted with undifferentiated cells on day 3 after plating. Cinnamaldehyde or thymol (both obtained from Danisco Animal Nutrition, DuPont Industrial Biosciences, Marlborough, UK) were dissolved in ethanol and diluted in growth medium without FBS or antibiotics to obtained the following concentrations: $5,15,50,100,250$ and $500 \mathrm{mg} \cdot 1^{-1}$ $(n=6$ for each treatment in each of the 3 independent experiments). The amount of ethanol was adjusted to $1 \%$ in each condition. The test samples were sterilefiltered through $0.2-\mu \mathrm{M}$-pore filters before use (Sartorius, Göettingen, Germany).

Caco- 2 cells were treated for $24 \mathrm{~h}$ with diluted cinnamaldehyde, thymol or their combination at doses of $15 \mathrm{mg} \cdot \mathrm{l}^{-1}$ thymol and $5 \mathrm{mg} \cdot \mathrm{l}^{-1}$ cinnamaldehyde (hereafter referred to as EO blend) in their nature-identical forms. The amount of cinnamaldehyde and thymol in the EO blend corresponded to the amount used in a commercial feed (g of Enviva ${ }^{\circledR}$ EO per tonne of feed; Danisco Animal Nutrition, DuPont Industrial Biosciences, Marlborough, UK). In these experiments, medium-only samples without ethanol or EOs were included as a control in which minimal LDH was released. The amount of released LDH was measured using the Cytotoxicity Detection Kit according to manufacturer's instruction (Roche Diagnostics $\mathrm{GmbH}$, Penzberg, Germany) with the use of spectrophotometer Spectramax 250 (Molecular Devices, Sunnyvale, CA, USA). The amount of released LDH due to the EOs and 1\% ethanol was normalized to that with medium alone by subtracting the value of the medium-only samples from that of the test samples and was expressed as percentage cytotoxicity $(\%$ cytotoxicity) from the $1 \%$ ethanol control.

For the cell proliferation assay, Caco-2 cells (70 000 cells P58, ECACC) were seeded in 96-well plates (Greiner Bio-One Ltd., Gloucestershire, UK) and incubated overnight in growth medium, then they were incubated for another $24 \mathrm{~h}$ in growth medium without FSB or antibiotics. The experiment was conducted on undifferentiated cells on day 3 after plating. Cinnamaldehyde and thymol were diluted in ethanol similarly as in the LDH assay, sterilefiltered as above, and incubated with the cells for $24 \mathrm{~h}$ ( $n=6$ in each of the 3 independent experiments). The amount of ethanol was adjusted to $1 \%$ in each well, and cell proliferation was measured using WST-1 assay according to manufacturer's instruction (Roche Diagnostics GmbH, Penzberg, Germany) with the use of spectrophotometer Spectramax 250 (Molecular Devices, Sunnyvale, CA, USA). The results were calculated by subtracting the value of the blank (culture medium plus WST-1) from that of the test samples and expressed as \% change from the 1\% ethanol control.

\section{Transepithelial electrical resistance (TEER) in differentiated Caco- 2 cells}

Caco-2 cells ( 66000 cells $/ \mathrm{cm}^{2}$, ATCC, P35)were differentiated as described in Putaala et al. (2008). Shortly, the cells were seeded in 12-well fibrillar collagen-coated cell culture inserts (Corning, New York, NY, USA) in Caco-2 maintenance medium without antibiotics in both apical and basolateral compartment and incubated overnight at $37{ }^{\circ} \mathrm{C}$ in a $5 \% \mathrm{CO}_{2}$ atmosphere with $95 \%$ humidity (Heracell 150i, Thermo Fisher Scientific, Waltham, MA, USA). On the following day, the medium was changed to Enterostim (Corning, New York, NY, USA) that was supplemented with MITO+ serum extender (differentiation medium) (Corning, New York, NY, USA) in both apical and basolateral compartments. The medium was changed on both sides to fresh differentiation medium on day 4 after seeding.

On day 5 of culturing, TEER (Millicell-ERS, Millipore, Billerica, MA, USA) was measured, and the monolayers at which the TEER exceeded $200 \mathrm{ohm} \times \mathrm{cm}^{2}$ were used. Cells were treated from the apical side with differentiation medium alone, $1 \%$ ethanol in differentiation medium, cinnamaldehyde or thymol at $5,15,50$ and $100 \mathrm{mg} \cdot \mathrm{ml}^{-1}$ doses, or with EO blend; all treatments were diluted in differentiation medium that was sterile-filtered as above, and ethanol amount was adjusted in each treatment to $1 \%$ as above prior to the experiment with the cells for $24 \mathrm{~h}(\mathrm{n}=3$ in each of the 3 independent experiments). TEER was measured from the inserts before and after treatment with differentiation medium alone, $1 \%$ ethanol in differentiation medium, cinnamaldehyde, thymol or EO blend. The TEER of the monolayer and insert was subtracted by the background TEER from an insert without cells to yield the monolayer resistance and multiplied by the area of the insert. The results were expressed as the $\%$ change in TEER after $24 \mathrm{~h}$ of treatment, corrected to the background by subtracting the resistance of cells that were treated with differentiation medium alone from resistance that of the treatments of $1 \%$ ethanol in differentiation medium, cinnamaldehyde, thymol or EO blend. 


\section{Real-Time RT-PCR analysis of $C O X 1$ and $C O X 2$ genes in differentiated Caco-2 cells}

After $24 \mathrm{~h}$ of treatment with cinnamaldehyde, thymol or EO blend, differentiated Caco- 2 cells as cultured above were lysed with RA1 buffer (Macherey-Nagel GmbH \& Co. KG, Duren, Germany) that was supplemented with $1 \% \beta$-mercaptoethanol (Sigma Aldrich, St. Louis, MO, USA). Total RNA was isolated using the NucleoSpin RNA kit (Macherey-Nagel GmbH \& Co., Duren, Germany), and reverse transcription was performed using Superscript III (Thermo Fisher Scientific, Waltham, MA, USA) with random primers according to manufacturers' instructions. The absolute levels of $C O X 1$ and $C O X 2$ were determined as described by Putaala et al. (2008) with the use of thermocycler ABI PRISM ${ }^{\circledR} 7000$ (Applied Biosystems, Foster City, CA, USA). The COX1:COX2 ratio was calculated as the amount of COX1 mRNA divided by that of COX2 mRNA.

\section{Comparison of pathogenic $E$. coli $\mathrm{O} 157: \mathrm{H7}$ and EO blend effects on TEER, and COX1 and $C O X 2$ genes expression}

E. coli O157:H7 (EHEC; DSM8579, DSMZ, Braunschweig, Germany) was cultured in LuriaBertani broth supplemented with $1.0 \%$ glucose aerobically at $37^{\circ} \mathrm{C}$ until an OD600 reading of 0.6-0.7 was obtained (Biophotometer, Eppendorf, Hamburg, Germany). The bacteria were removed by centrifugation at $3000 \mathrm{~g}$ for $5 \mathrm{~min}$ at $25^{\circ} \mathrm{C}$ (Beckman Coulter, Brea, CA, US) and the supernatant (cellfree metabolites, CFMs) was stored at $-20{ }^{\circ} \mathrm{C}$ until used. To compare the effects of EO blend and EHEC CFMs in differentiated Caco-2 cells, EHEC CFMs were diluted $5 \%(\mathrm{v} / \mathrm{v})$ in differentiation medium. All test media, including 5\% EHEC CFM, 1\% ethanol, the medium-only control and EO blend, were sterile-filtered as above, and the ethanol adjusted to $1 \%$ in each treatment as above. Caco- 2 cells (ATCC, P35) were differentiated as above in 12-well inserts, and the treatment media were applied to the cells on day 5 in culture as above ( $n=3$ in each of the 3 independent experiments). The test media were replaced after $24 \mathrm{~h}$, and TEER values were measured after each 24 -hour interval. The $\%$ change in TEER after each $24 \mathrm{~h}$ ( 24 and $48 \mathrm{~h}$ ) was calculated as above but without normalization to the medium, because the medium-treated samples served as a control. The $C O X 1$ and $C O X 2$ genes expression was measured after $48 \mathrm{~h}$ of treatment as above.

\section{Statistical analyses of LDH assay, WST-1 assay, TEER and gene expression (Real-Time RT-PCR method)}

The significance of differences between treatments was analysed by two-tailed Student's t-test in GraphPad Prism version 5.01 (GraphPad Software, Inc., La Jolla, CA, USA). $P$-values of 0.05 or less were considered to be significant. All comparisons were made against the respective $1 \%$ ethanol control. Pearson correlation coefficients were calculated between TEER and gene expression values. For statistical analysis data from three independent experiments were combined. Mean plus/minus standard error (SE) is shown for all assays.

\section{Gene array hybridization}

Differentiated Caco-2 cells (66 000 cells $/ \mathrm{cm}^{2}$, ATCC, P35; differentiated as above) were treated with $1 \%$ ethanol as a control and with EO blend for $48 \mathrm{~h}$ from the apical side, as described above. Total RNA was isolated as described above. To obtain enough amount of RNA $(1 \mu \mathrm{g})$ for analysis of human cell transcriptome with the use of Affymetrix U133+2.0 Gene Chips (Affymetrix Inc., Santa Clara, CA, USA), three samples, each from three independent experiment, were combined. The obtained combined samples from control and EOtreated cells were analysed in three replicates. All RNA was processed, labelled, hybridized, washed, stained and scanned according to the manufacturer's (Affymetrix Inc., Santa Clara, CA, USA) recommendations at AROS Applied Technology (Aarhus, Denmark).

Microarray data were pre-processed with GC-RMA and analysed statistically using R (version 2.5.0) and Bioconductor (version 2.0) as in Putaala et al. (2010). Every analysis used logtransformed data as output by GC-RMA. The data quality was assessed by RNA digestion blot for the raw and normalized data; no deviations indicating quality problems were observed in these analyses (data not shown). The signal intensity was low; thus, a change in gene expression by more than $0.8 \log$-ratio and $P=0.1$ in the signal intensity was observed in comparison with that of the $1 \%$ ethanol control used as the cutoff for selecting differentially regulated genes. The raw data were deposited into the NCBI Gene Expression Omnibus database under GEO series accession number GSE28792. 

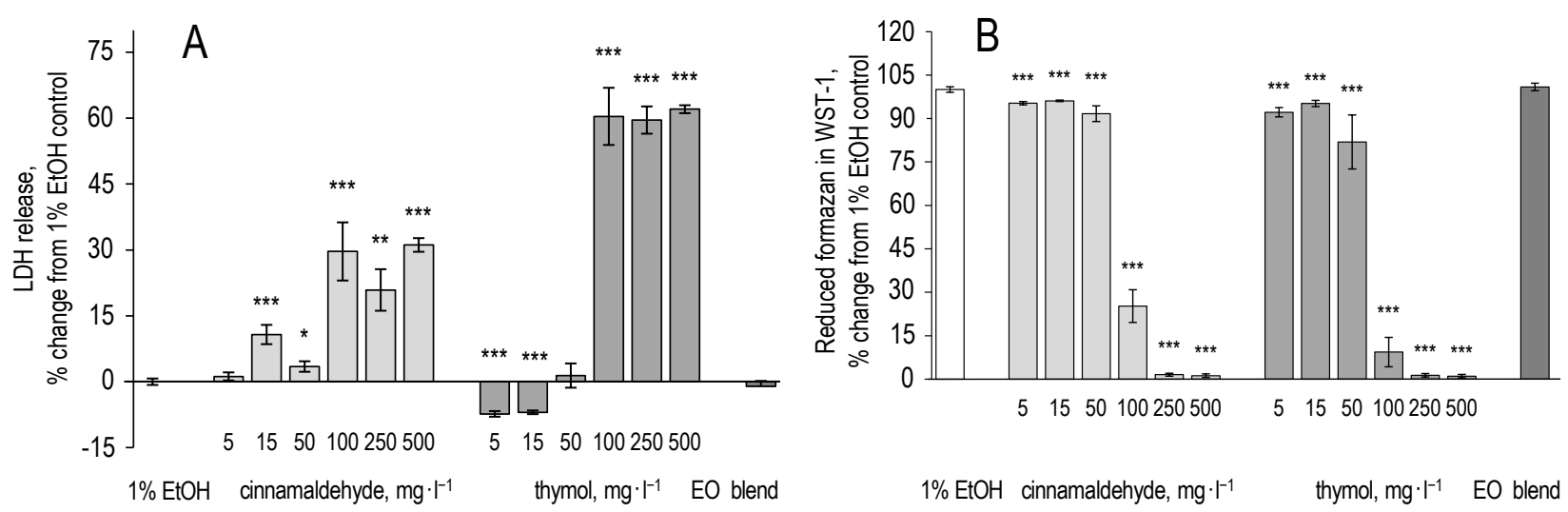

$1 \% \mathrm{EtOH}$ cinnamaldehyde, $\mathrm{mg} \cdot \mathrm{l}^{-1} \quad$ thymol, $\mathrm{mg} \cdot \mathrm{l}^{-1} \quad \mathrm{EO}$ blend

Figure 1. Effect of cinnamaldehyde, thymol and essential oils (EO) blend $\left(5 \mathrm{mg} \cdot \mathrm{I}^{-1}\right.$ cinnamaldehyde, $15 \mathrm{mg} \cdot \mathrm{I}^{-1}$ thymol) on lactate dehydrogenase (LDH) (A), and on formazan by WST-1 assay (B) expressed as percentage change from the $1 \%$ EtOH control. The asterisks denote the statistically significant difference from $1 \% \mathrm{EtOH}$ control: ${ }^{*}-P<0.05,{ }^{* *}-P<0.01, * * *-P<0.001$

\section{Results}

Cinnamaldehyde, thymol and their combination (EO blend) do not induce membrane permeabilization or compromise cell proliferation

To determine whether cinnamaldehyde and thymol cause cellular membrane permeabilization or affect cellular proliferation, cinnamaldehyde, thymol and their combination were applied to undifferentiated Caco-2 cells, and LDH activity and WST-1 dye cleavage were quantified.

LDH release was significantly higher only when doses of cinnamaldehyde or thymol were applied equal or greater than $100 \mathrm{mg} \cdot 1^{-1}$ even though some slight increase was noted by cinnamaldehyde already at $15 \mathrm{mg} \cdot \mathrm{l}^{-1}$ (Figure $1 \mathrm{~A}$ ). The $\% \mathrm{LDH}$ release that was induced by cinnamaldehyde at 100 to $500 \mathrm{mg} \cdot 1^{-1}$ was $20.9 \pm 4.7 \%$ to $31.1 \pm 1.6 \%$, which was generally lower than with thymol at the same doses $(59.6 \pm 3.1 \%$ to $62.0 \pm 0.9 \%)$. No LDH release was detected with the EO blend.

Both cinnamaldehyde and thymol started to decrease the proliferation slightly at low amounts 5 to $15 \mathrm{mg} \cdot 1^{-1}$, but a more substantial decrease in proliferation was noted starting at $50 \mathrm{mg} \cdot \mathrm{1}^{-1}$ of the EOs (Figure 1B). The proliferation did not differ from the control when EO blend was examined.

\section{Cinnamaldehyde, thymol and their combination (EO blend) regulate TEER, and $C O X 1$ and $C O X 2$ gene expression differentially in intestinal epithelial cells}

The effects of EOs on TJs were measured by TEER in differentiated Caco-2 cells. Cinnamaldehyde lowered TEER values significantly by $-28.3 \pm 0.3 \%$ at $50 \mathrm{mg} \cdot \mathrm{ml}^{-1}(P<0.001)$ and by
$-76.8 \pm 0.3 \%$ at $100 \mathrm{mg} \cdot 1^{-1}(P<0.001$; Figure $2 \mathrm{~A})$. In contrast, thymol increased TEER by $6.9 \pm 2.6 \%$ at $15 \mathrm{mg} \cdot 1^{-1}(P<0.05)$, which was even higher $49.7 \pm 5.3 \%$ and $61.7 \pm 5.4 \%$ at $50 \mathrm{mg} \cdot 1^{-1}(P<0.001)$ and $100 \mathrm{mg} \cdot 1^{-1}$, respectively $(P<0.001)$. Notably, EO blend raised TEER values also significantly by $49.7 \pm 4.4 \%(P<0.001)$.

Cinnamaldehyde and thymol differentially regulated $C O X 1$ gene expression (Figure 2B) but no change in $C O X 2$ expression was observed after each of EOs addition (Figure 2C). In thymol-treated cells, COXI gene expression rose significantly at $15 \mathrm{mg} \cdot 1^{-1}(P<0.05)$, while a tendency to increase $C O X 1$ gene amount was observed at 50 and $100 \mathrm{mg} \cdot 1^{-1}$ doses $(P=0.067$ and $P=0.072$, respectively). With EO blend, no effect on the gene expression of $C O X 1$ was observed, while COX2 gene expression increased modestly, without reaching significance due to high variance.

The COX1:COX2 ratio decreased with cinnamaldehyde significantly at $50 \mathrm{mg} \cdot 1^{-1}$ and $100 \mathrm{mg} \cdot \mathrm{1}^{-1}$ (Figure 2D). With thymol, the COX1:COX2 ratio at first increased significantly at $15 \mathrm{mg} \cdot 1^{-1}$ and $50 \mathrm{mg} \cdot \mathrm{l}^{-1}$ and then reverted to basal level at $100 \mathrm{mg} \cdot 1^{-1}$. No change in COX1:COX2 ratio was noted with EO blend.

A positive correlation between TEER and COX1 gene expression was observed $(r=0.6282$, $P=0.0003$ ), and a weaker association was seen between TEER and COX2 gene expression $(\mathrm{r}=0.4084$, $P=0.0310)$. There was no correlation between TEER values and the COX1:COX2 ratio.

\section{The increase in $C O X 2$ gene expression by $\mathrm{EO}$ blend is modest in comparison with EHEC}

Based on the slight increase in $C O X 2$ gene expression with EO blend (Figure 2C), the determination whether this rise reflected a similar response 

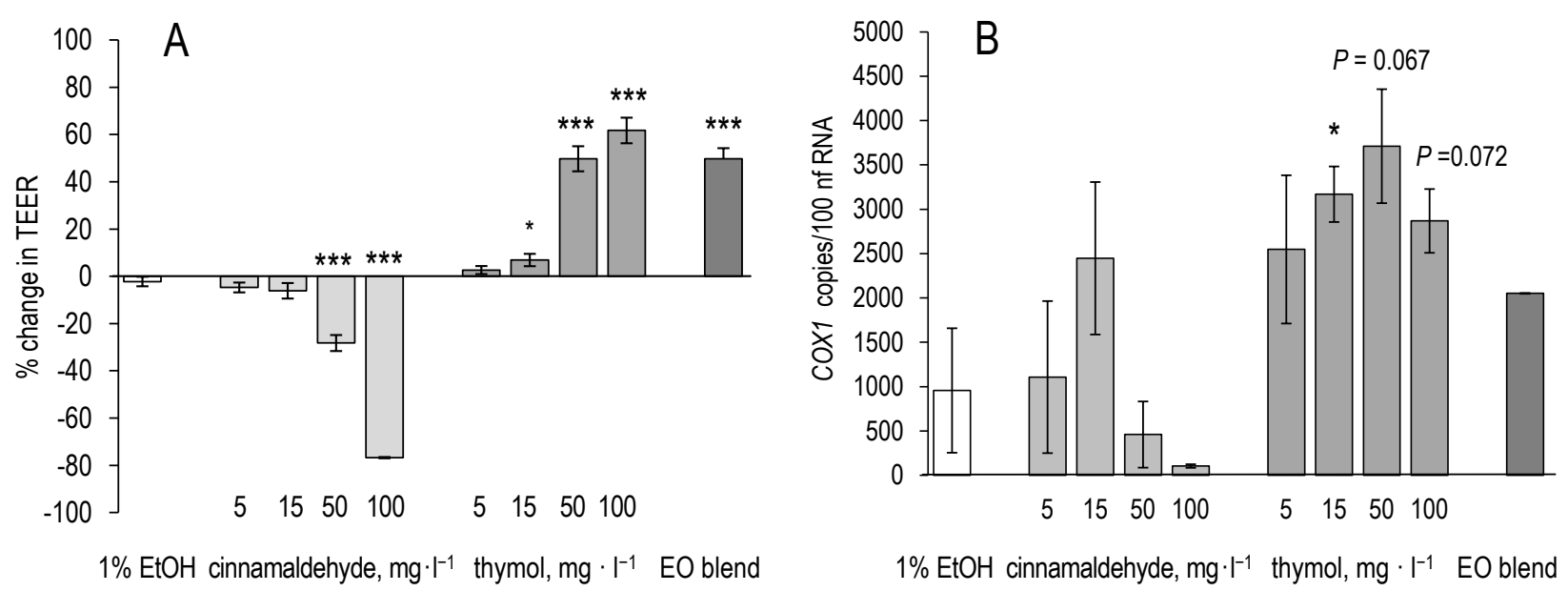

$1 \%$ EtOH cinnamaldehyde, $\mathrm{mg} \cdot \mathrm{l}^{-1}$ thymol, $\mathrm{mg} \cdot \mathrm{l}^{-1}$ EO blend

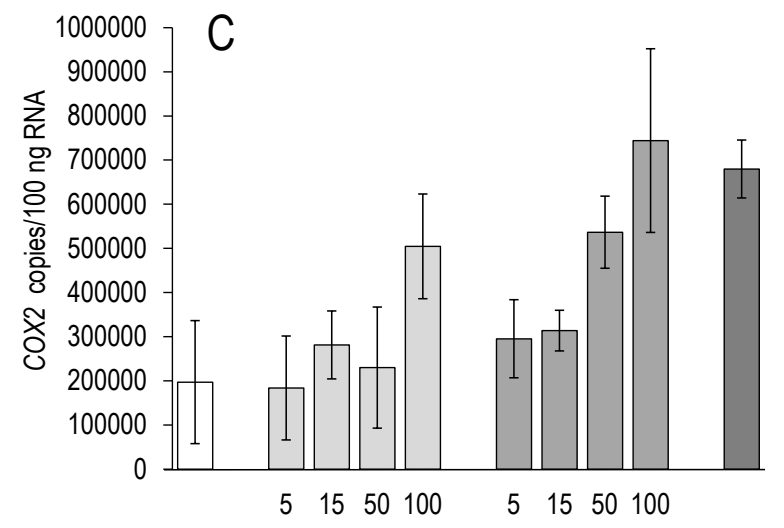

$1 \% \mathrm{EtOH}$ cinnamaldehyde, $\mathrm{mg} \cdot \mathrm{l}^{-1}$ thymol, $\mathrm{mg} \cdot \mathrm{l}^{-1}$ EO blend

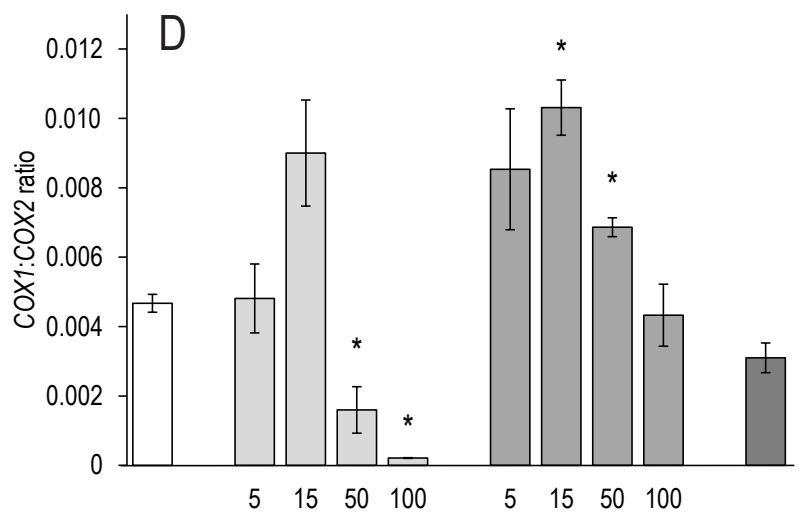

$1 \%$ EtOH cinnamaldehyde, $\mathrm{mg} \cdot \mathrm{l}^{-1}$ thymol, $\mathrm{mg} \cdot \mathrm{l}^{-1} \mathrm{EO}$ blend

Figure 2. Effect of cinnamaldehyde, thymol and essential oils (EO) blend $\left(5 \mathrm{mg} \cdot \mathrm{I}^{-1}\right.$ cinnamaldehyde, $15 \mathrm{mg} \cdot \mathrm{I}^{-1}$ thymol) on transepithelial electrical resistance (TEER) (A), COX1 gene expression (B), COX2 gene expression (C) and COX1:COX2 ratio (D). The asterisks denote the statistically significant difference from $1 \% \mathrm{EtOH}$ control: $*-P<0.05, * * *-P<0.001$

as with EHEC CFM treatment was performed. Also, the incubation time was increased to up to $48 \mathrm{~h}$ to examine whether this response became more extensive over time.

As 5\% (vol/vol) dilution, the EHEC metabolites decreased TEER values after $24 \mathrm{~h}$ to $2.0 \pm 2.8 \%$ $(P<0.01)$, which continued to decline after another $24 \mathrm{~h}(48 \mathrm{~h})$ of incubation by $45.8 \pm 2.0 \%(P<0.001$; Figure $3 \mathrm{~A})$. In contrast, EO blend increased TEER by $163.7 \pm 6.9 \%(P<0.05)$ after the first $24 \mathrm{~h}$, but no effect on TEER was observed after additional $24 \mathrm{~h}$ of incubation.

In EHEC CFM-treated Caco-2 cells, $C O X 1$ gene expression declined $(P<0.001$; Figure $3 \mathrm{~B})$, and that of $C O X 2$ rose 6-fold (Figure 3C) $(P<0.001)$. Pathogenic EHEC also lowered COX1:COX2 ratio $(P<0.001$; Figure 3D).

EO blend affected disparate gene expression pattern in comparison with EHEC CFM treatment. EO blend significantly increased $C O X 1$ expression $(P<0.05$; Figure 3B), and decreased $C O X 2$ expres- sion in comparison with the EHEC CFM treatment $(P<0.001$; Figure 3C). These changes in $C O X 1$ and $C O X 2$ genes expression with EO blend translated into COX1:COX2 ratio that differed significantly from the EHEC CFM treatment $(P<0.01$; Figure 3D).

In the correlation analysis, TEER and $C O X 1$ gene expression were positively associated $(\mathrm{r}=0.6425$, $P<0.05$ ), whereas a negative correlation was observed between TEER and COX2 gene expression $(\mathrm{r}=-0.9319, P<0.0001)$. Additionally, the COX1:COX2 ratio correlated positively with TEER $(\mathrm{r}=0.8162, P<0.001)$.

\section{Combination of cinnamaldehyde and thymol affects limited set of genes}

The long-term effects of EO blend on gene expression in differentiated Caco-2 cells after $48 \mathrm{~h}$ were examined. Differentially expressed genes were selected, based on a cutoff of 0.8 , due to low signal intensity. EO blend regulated 33 genes -23 genes were down-regulated and 10 - up-regulated (Table 1). 

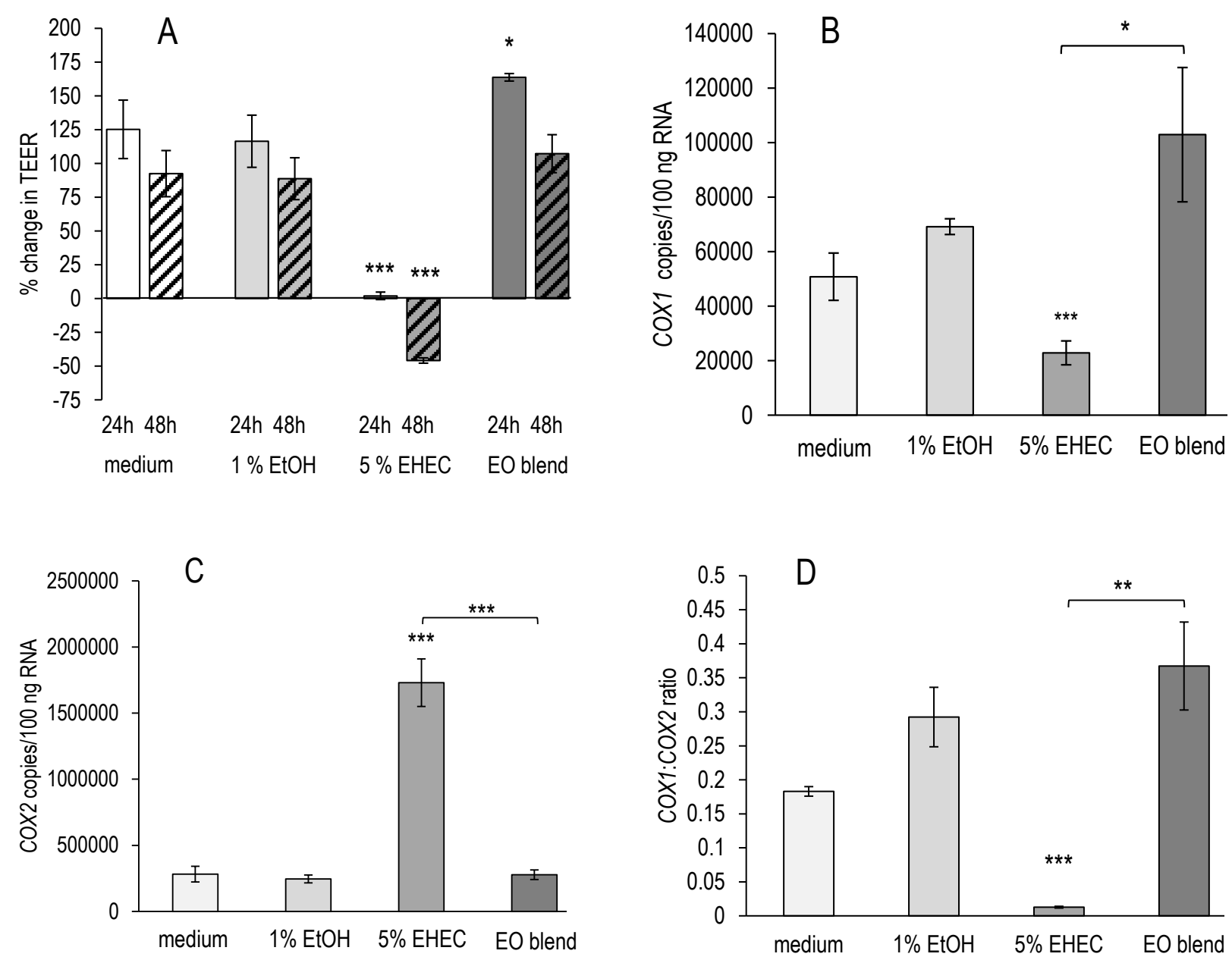

Figure 3. Effect of Caco-2 treatment with essential oils (EO) blend $\left(5 \mathrm{mg} \cdot \mathrm{I}^{-1}\right.$ cinnamaldehyde, $15 \mathrm{mg} \cdot \mathrm{I}^{-1}$ thymol) and $5 \%$ cell-free pathogenic Escherichia coli 0157:H7 (EHEC)-conditioned medium on transepithelial electrical resistance (TEER) after 24 and $48 \mathrm{~h}(\mathrm{~A})$, COX1 gene expression (B), COX2 gene expression (C) and COX1:COX2 ratio (D) after $48 \mathrm{~h}$.

$1 \% \mathrm{EtOH}-1 \%$ ethanol dilution; the asterisks denote the statistically significant difference between $1 \% \mathrm{EtOH}$ and EHEC (asterisks above EHEC bar) or between EO blend and EHEC bar (asterisks above line): * $-P<0.05, * *-P<0.01, * * *-P<0.001$

There was no distinct set of genes that was governed, and by Gene Ontology analysis (data not shown), no specific gene group was regulated by EO blend.

Table 1. Thirty three genes that were differentialy upregulated and downregulated by cinnamaldehyde $\left(5 \mathrm{mg} \cdot \mathrm{l}^{-1}\right)$ and thymol $\left(15 \mathrm{mg} \cdot \mathrm{l}^{-1}\right)$ essential oils (EO) blend in differentiated Caco-2 cells treated apically for $48 \mathrm{~h}$

\begin{tabular}{llll}
\hline \multicolumn{3}{l}{ Upregulated genes } \\
\hline 238320_at & EFCAB4B & LOC400756 & 239338_x_at \\
TMSB15A & 238042_at & MSR1 & \\
PPAN & IGF2BP3 & ECE1 & \\
\hline Downregulated genes & & \\
\hline ZC3H11A & ATP11B & TTC37 & 1557864_x_at \\
232535_at & NUP54 & GPR128 & FAM81B \\
1555978_S_at & ARAP2 & CHD2 & LOC400550 \\
MEF2A & FGD6 & HOXA13 & MAP1LC3A \\
CYP1B1 & ESC01 & HMGA2 & C160rf70 \\
CP & LARP4 & KIAA0196 & \\
\hline
\end{tabular}

\section{Discussion}

The aim of the study was to evaluate the direct effects of cinnamaldehyde and thymol on intestinal epithelial cells, TJs, and COX genes expression. The combination of cinnamaldehyde and thymol is used in animal feeding at similar amounts as in this study.

There are several limitations of using Caco-2 cell monocultures to compare the complexity of the gut. Notably, the contacts with natural microbiota and mucosal immune system of the gut are absent, for example. When nutrients are ingested by an animal, they can be fermented by the intestinal microbiota, and the produced metabolites can have different effects on intestinal epithelial cells, as observed for dietary polyphenols in human diet (Veeriah et al., 2007). The concentrations of cinnamaldehyde and thymol in the ileal and caecal contents of chickens are $0.2 \%$ to $4 \%$ of that in the feed (Nurminen et al., unpublished 
results), indicating that these EOs are absorbed and metabolized by the host or gut microbes. However, the Caco-2 intestinal epithelium cell model has been widely used for over three decades. With regard to the Replacement, Reduction, and Refinement (3Rs) approach for animal trials, the Caco-2 cell line is useful in initial screening of feed additives.

In this study, the effects of intact compounds, not their fermentates, were measured and it would be interesting to determine whether these types of differences exist between fermented and non-fermented cinnamaldehyde and thymol. Further, in a chicken study, the levels of short-chain fatty acids and biogenic amines change on administration of cinnamaldehyde and thymol combination (Tiihonen et al., 2010). Because short-chain fatty acids can be used as an energy source by the gut epithelial cells, they can have significant effects on gut epithelial cells health (Józefiak et al., 2004). When EO blend ( $5 \mathrm{mg} \cdot 1^{-1}$ cinnamaldehyde and $15 \mathrm{mg} \cdot 1^{-1}$ thymol) was applied to Caco-2 cells, no adverse effects in terms of cellular membrane permeabilization or proliferation were observed. Moreover, EO blend improved TJ integrity and thus might have protective functions in intestinal epithelial cells.

An important property of EOs is their hydrophobicity, which allows them to permeabilize cellular or organelle membranes and influence cell metabolism, a property that is important in cytotoxicity and growth prevention of the prokaryotic pathogens (Bakkali et al., 2008; Reichling et al., 2009). Permeabilization of the outer and inner mitochondrial membranes in eukaryotic cells causes apoptosis and necrosis, and as putative prooxidants, EOs may cause mitochondrial dysfunction (Bouayed and Bohn, 2010). Thymol and cinnamaldehyde do not alter cell membrane permeabilization up to $50 \mathrm{mg} \cdot 1^{-1}$ dose and proliferation until at $50 \mathrm{mg} \cdot 1^{-1}$ amount. The slight increase in LDH release by cinnamaldehyde at amount 15 and $50 \mathrm{mg} \cdot \mathrm{1}^{-1}$ may reflect, as noted in the WST-1 analysis, a decrease in number of metabolically active cells, which might undergo apoptosis and cytolysis releasing LDH. This kind of slight effect in membrane permeabilization and proliferation can be anticipated when cancer cells, such as undifferentiated Caco-2 cells, are utilized as in vitro model. Thymol does not cause significant apoptosis or necrosis (Llana-Ruiz-Cabello et al., 2015), and this finding is supported by our study. Similarly, cinnamaldehyde is not cytotoxic at low amounts (Huang et al., 2011). Accordingly, our results show that there was no cytotoxicity of thymol or cinnamaldehyde at lower doses, up to $50 \mathrm{mg} \cdot 1^{-1}$, and more importantly, for their combination $\left(15 \mathrm{mg} \cdot 1^{-1}\right.$ thymol and $5 \mathrm{mg} \cdot 1^{-1}$ cinnamaldehyde), representing commercial relevance dose.

Phenolic compounds commonly have protective and deleterious effects that depend on the dose (Bouayed and Bohn, 2010). Thymol and cinnamaldehyde have marginal toxic effects in vivo or do not have effect at all, whereas the cellular toxicity that was observed in vitro at higher amounts might be attributed to the route of exposure to be more sensitive. Cinnamaldehyde and thymol, combined with other EOs to $900 \mathrm{mg} \cdot \mathrm{kg}^{-1}$ feed, in a dose that is 45 times higher than in the commercial feed, do not have any adverse effects on performance (growth, feed conversion ratio) or intestinal health (small intestinal crypt:villus ratio, and expression of interferon (IFN)- $\gamma$ ) in chickens (Nurminen et al., unpublished results). The bioavailability of cinnamaldehyde and thymol might limit any toxic effects that arise. No free cinnamaldehyde or thymol was detected in liver tissue from 3-week-old chickens that were fed diet with $100 \mathrm{mg} \cdot \mathrm{kg}^{-1}$ cinnamaldehyde or $100 \mathrm{mg} \cdot \mathrm{kg}^{-1}$ thymol for 3 days (Saarinen, unpublished results). Most absorbed cinnamaldehyde is metabolized rapidly to hippuric acid and excreted in urine (Yuan et al., 1992). Thymol is metabolized to thymol sulphate and thymol glucuronide, and approximately $16 \%$ of the thymol dose is secreted as these metabolites in urine (Kohlert et al., 2002). However, on ultrastructural morphological examination by electron microscopy, cell death is induced, as seen in Caco-2 cells with $250 \mu \mathrm{M}$ thymol treatment for 24 and $48 \mathrm{~h}$, despite no cytotoxicity being observed (Llana-Ruiz-Cabello et al., 2014). In our study, the doses of thymol ranged from 0.033 to $3.3 \mu \mathrm{M}$, and ultrastructural changes indicating cytotoxicity are unlikely to happen.

$C O X 2$ is an early inflammation-related gene that is activated by bacterial lipopolysaccharide (LPS) through nuclear factor kappa B (NF-kB) (Simmons et al., 2004), whereas $C O X 1$ is homeostatic (Burdan et al., 2008). Thymol has been observed to inhibit COX-1 and COX-2 activity (Marsik et al., 2005). COX-1 is considered a conditional homeostatic enzyme that is involved in tissue maintenance, and when it is inhibited, COX-2 takes part in prostaglandins generation. Thus, under physiological condition, COX-2 protein and activity levels are low (Matsui et al., 2011). This inhibition of COX-1 activity by thymol observed by Marsik et al. (2005) is inconsistent with our findings, wherein thymol up-regulated COX1 gene expression. This contradiction may be attributed to differences in measurements - whereas Marsik et al. (2005) measured enzyme activity, in 
this study the gene expression was analysed - which cannot be translated directly into enzymatic activity. However, this fact suggests that the activities of COX enzymes when treated with thymol can be re-evaluated with other assays on enzymatic activity.

As an inducible enzyme, COX-2 has been implicated in proinflammatory signalling, and its transcription is up-regulated, for instance, during stimulation with pathogenic enterohemorrhagic E. coli (Putaala et al., 2008). Thymol and cinnamaldehyde did not alter $C O X 2$ transcript levels in our study to a large extend. Notably, after $24 \mathrm{~h}$ and $48 \mathrm{~h}$ of incubation, increase in the COX1:COX2 ratio with $\mathrm{EO}$ blend was negligible compared to either $1 \%$ ethanol or untreated control mirroring the situation in healthy cells, in which COX-1 is more abundant for intestinal maintenance and COX-2 is considered for signal inflammation (Simmons et al., 2004; Burdan et al., 2008). Cinnamaldehyde and thymol have been indicated to be anti-inflammatory. Thymol scavenges reactive oxygen species (ROS) in neutrophils (Braga et al., 2006). Cinnamaldehyde inhibits ROS production (Chao et al., 2008) to impede NF- $\kappa$ B activation (Youn et al., 2008), consequently suppressing proinflammatory targets, such as cytokines, and LPSinduced COX2 gene expression (Chao et al., 2008; Youn et al., 2008). In connection with the lack of supression of COX2 gene expression in Caco-2 cells in physiological state, the experiment with LPS-induced $\mathrm{COX} 2$ gene expression prior to $\mathrm{EO}$ treatment needs to be conducted in the future.

The effects of thymol and cinnamaldehyde on intestinal tissue resistance have been studied by Michiels et al. (2010) and Boudry and Perrier (2008). In the latter experiment, cinnamaldehyde and thymol did not affect TEER (Boudry and Perrier, 2008), whereas in the former, in contrast to results of our study, cinnamaldehyde increased resistance slightly (Michiels et al., 2010). The reason for this discrepancy in not known. Tight junctions can regulate the magnitude of fluid flow through the paracellular pathway by opening their pores (Ulluwishewa et al., 2011). Intestinal fluid flux also increases with bacterial toxins - TEER declined on treatment with EHEC cell-free metabolites (Putaala et al., 2008). However, the amounts of cinnamaldehyde and thymol in Michiels et al. (2010) were higher than those of standard animal feed, which might be the reason for the inconsistency.

Tight junctions act as a seal to prevent translocation of luminal bacteria across the epithelial layer (Ulluwishewa et al., 2011), and in vivo trials should be performed to determine whether the effects of EOs in vitro have any biological relevance. In our study, cinnamaldehyde alone lowered TJ integrity, but no such effect was seen with EO blend. This suggests that thymol might have compensated the TEER-decreasing effect of cinnamaldehyde in the EO blend. Furthermore, the increase due to EO blend was more extensive than that of $15 \mathrm{mg} \cdot \mathrm{1}^{-1}$ thymol alone at an equal concentration. Enhanced resistance of the permeability barrier might be beneficial in preventing bacterial translocation and penetration of toxins and other luminal content inside of the body. The effects on permeability in vitro and in vivo could be studied further using various molecular markers and testing various pathogens to determine whether EOs protect against bacterial translocation, for example. The negative correlation between $C O X 2$ gene expression and TEER has been reported (Putaala et al., 2008), which is logical - if resistance decreases, more luminal compounds will pass through and elicit inflammatory responses. However, the decrease in TEER caused by cinnamaldehyde does not indicate that thymol could be solely used in the feed to obtain the same characteristics as the combination has in vivo, since cinnamaldehyde has, for instance high pathogen growth reducing capacity, which provides additional benefits to the combination (Ouwehand et al., 2010).

By gene expression profiling, the EO blend affected only 33 genes after $48 \mathrm{~h}$. In this analysis a low cutoff of 0.8 was used, because the signal intensity was low. No specific gene ontology class was enriched. Because there were few differentially expressed genes, shorter time periods should be used to determine the more acute effects of cinnamaldehyde and thymol; it is presumed that presented data reflect rather long-term effects.

Thymol can in vivo affect electrogenic anion secretion that is mediated by the Transient receptor potential cation channel subfamily A member 1 (TRPA1) channel (Kaji et al., 2011). Cinnamaldehyde, in turn, can release 5-hydroxytryptamine (5-HT, or serotonin) through stimulation of TRPA1 in enterochromaffin cells that have been isolated from rat small intestine (Nozawa et al., 2009). In the GI tract, TRPA1 is involved in the mobility of the small intestine and gastric emptying (Nozawa et al., 2009). Functional TRPA1 channels are also expressed by enterocytes of the duodenum and colon in the mouse intestine, and it has been suggested that TRPA1 activation in enterocytes enhances digestive efficiency and facilitates nutrient absorption (Fothergill et al., 2016). TRPA1 activity has been also detected in chickens. In addition, cinnamaldehyde reduces serum leptin and increases serum ghrelin levels, two hormones that modulate hunger and satiety, in high-fat-diet-fed mice but not 
in control mice that have been given cinnamaldehyde (Khare et al., 2016). In contrast to mammals, in birds, ghrelin inhibits feed intake (Boswell and Dunn, 2015). There is controversy about the function of leptin in birds; it has been suggested to be more pleiotropic in birds and not primarily involved in regulating energy balance (Boswell and Dunn, 2015). It remains to be determined whether and how thymol and cinnamaldehyde participate in TRPA1 activation or in the regulation of ghrelin and leptin in vivo in chickens.

\section{Conclusions}

In conclusion, cinnamaldehyde and thymol at $5 \mathrm{mg} \cdot 1^{-1}$ and $15 \mathrm{mg} \cdot 1^{-1}$ doses, respectively, and administered as a combination, have no adverse effects on cellular membrane permeabilization or cellular viability in intestinal epithelial cells. Although some regulation of cyclooxygenase genes expression was observed, the pattern differed from that induced by Escherichia coli $\mathrm{O} 157: \mathrm{H7}$. This combination also improved tight junction integrity in the Caco- 2 cell model and might have protective influence on intestinal epithelial cells.

\section{Acknowledgement}

Mrs. Jaana Oksanen is thanked for her skillful laboratory assistance.

\section{References}

Amerah A.M., Ouwehand A.C., 2016. Use of essential oils in poultry production. In: V.R. Preedy (Editor). Essential Oils in Food Preservation, Flavor and Safety. Academic Press. San Diego, CA (USA), pp. 101-110, https://doi.org/10.1016/B978-0-12416641-7.00010-9

Bakkali F., Averbeck S., Averbeck D., Idaomar M., 2008. Biological effects of essential oils - a review. Food Chem. Toxicol. 46, 446-475, https://doi.org/10.1016/j.fct.2007.09.106

Boswell T., Dunn I.C., 2015. Regulation of the avian central melanocortin system and the role of leptin. Gen. Comp. Endocrinol. 221, 278-283, https://doi.org/10.1016/j.ygcen.2014.12.009

Bouayed J., Bohn T., 2010. Exogenous antioxidants - double-edged swords in cellular redox state: health beneficial effects at physiologic doses versus deleterious effects at high doses. Oxidative Med. Cell. Longev. 3, 228-237, https://doi. org/10.4161/oxim.3.4.12858

Boudry G., Perrier C., 2008. Thyme and cinnamon extracts induce anion secretion in piglet small intestine via cholinergic pathways. J. Physiol. Pharmacol. 59, 543-552

Braga P.C., Dal Sasso M., Culici M., Galastri L., Marceca M.T., Guffanti E.E., 2006. Antioxidant potential of thymol determined by chemiluminescence inhibition in human neutrophils and cell-free systems. Pharmacology 76, 61-68, https://doi. org/10.1159/000089719
Burdan F., Szumiło J., Gajjar B., Dudka J., Korobowicz A., Patel S., Nat A., Nat A.S., Dworzański W., Kwaśniewski W., 2008. Immunoexpression of constitutive and inducible cyclo-oxygenase isoforms in the rat foetal and maternal digestive tract. Folia Morphol. 67, 24-31

Chao L.K., Hua K.-F., Hsu H.-Y., Cheng S.-S., Lin I-F., Chen C.-J., Chen S.-T., Chang S.-T., 2008. Cinnamaldehyde inhibits pro-inflammatory cytokines secretion from monocytes/ macrophages through suppression of intracellular signaling. Food Chem. Toxicol. 46, 220-231, https://doi.org/10.1016/j. fct.2007.07.016

Fothergill L.J., Callaghan B., Rivera L.R., Lieu T.M., Poole D.P., Cho H.-J., Bravo D.M., Furness J.B., 2016. Effects of food components that activate TRPA1 receptors on mucosal ion transport in the mouse intestine. Nutrients 8,623 , https://doi. org/10.3390/nu8100623

Huang T.-C., Chung Y.-L., Wu M.-L., Chuang S.-M., 2011. Cinnamaldehyde enhances Nrf2 nuclear translocation to upregulate phase II detoxifying enzyme expression in HepG2 cells. J. Agric. Food Chem. 59, 5164-5171, https://doi.org/10.1021/jf200579h

Hughes P., Marshall D., Reid Y., Parkes H., Gelber C., 2007. The costs of using unauthenticated, over-passaged cell lines: how much more data do we need? BioTechniques 43, 575-586, https:// doi.org/10.2144/000112598

Józefiak D., Rutkowski A., Martin S.A., 2004. Carbohydrate fermentation in the avian ceca: a review. Anim. Feed Sci. Technol. 113, 1-15, https://doi.org/10.1016/j.anifeedsci.2003.09.007

Kaji I., Karaki S.-i., Kuwahara A., 2011. Effects of luminal thymol on epithelial transport in human and rat colon. Am. J. Physiol. Gastrointest. Liver Physiol. 300, G1132-G1143, https://doi. org/10.1152/ajpgi.00503.2010

Khare P., Jagtap S., Jain Y. et al., 2016. Cinnamaldehyde supplementation prevents fasting-induced hyperphagia, lipid accumulation, and inflammation in high-fat diet-fed mice. BioFactors 42, 201-211, http://onlinelibrary.wiley.com/ doi/10.1002/biof.1265/full

Kohlert C., Schindler G., März R.W., Abel G., Brinkhaus B., Derendorf H., Gräfe E.-U., Veit M., 2002. Systemic availability and pharmacokinetics of thymol in humans. J. Clin. Pharmacol. 42, 731-737, https://doi.org/10.1177/009127002401102678

Llana-Ruiz-Cabello M., Gutiérrez-Praena D., Pichardo S., Moreno F.J., Bermúdez J.M., Aucejo S., Cameán A.M., 2014. Cytotoxicity and morphological effects induced by carvacrol and thymol on the human cell line Caco-2. Food Chem. Toxicol. 64, 281-290, https://doi.org/10.1016/j.fct.2013.12.005

Llana-Ruiz-Cabello M., Gutiérrez-Praena D., Puerto M., Pichardo S., Jos Á., Cameán A.M., 2015. In vitro pro-oxidant/antioxidant role of carvacrol, thymol and their mixture in the intestinal Caco-2 cell line. Toxicol. Vitro 29, 647-656, https://doi.org/10.1016/j.tiv.2015.02.006

Marsik P., Kokoska L., Landa P., Nepovim A., Soudek P., Vanek T., 2005. In vitro inhibitory effects of thymol and quinones of $\mathrm{Ni}$ gella sativa seeds on cyclooxygenase-1- and -2-catalyzed prostaglandin $\mathrm{E}_{2}$ biosyntheses. Planta Med. 71, 739-742, https://doi.org/10.1055/s-2005-871288

Matsui H., Shimokawa O., Kaneko T., Nagano Y., Rai K., Hyodo I., 2011. The pathophysiology of non-steroidal anti-inflammatory drug (NSAID)-induced mucosal injuries in stomach and small intestine. J. Clin. Biochem. Nutr. 48, 107-111, https://doi. org/10.3164/jcbn.10-79

Michiels J., Missotten J., Dierick N., Fremaut D., De Smet S., 2010. Thymol and trans-cinnamaldehyde reduce active nutrient absorption and chloride secretion in the pig jejunal Ussing chamber model. Livest. Sci. 134, 27-29, https://doi.org/10.1016/j. livsci.2010.06.087 
Nozawa K., Kawabata-Shoda E., Doihara H. et al., 2009. TRPA1 regulates gastrointestinal motility through serotonin release from enterochromaffin cells. Proc. Natl. Acad. Sci. USA. 106 3408-3413, https://doi.org/10.1073/pnas.0805323106

Ouwehand A., Tiihonen K., Kettunen H., Peuranen S., Schulze H., Rautonen N., 2010. In vitro effects of essential oils on potential pathogens and beneficial members of the normal microbiota. Vet. Med. 55, 71-78

Putaala H., Barrangou R., Leyer G.J., Ouwehand A.C., Bech Hansen E., Romero D.A., Rautonen N., 2010. Analysis of the human intestinal epithelial cell transcriptional response to Lactobacillus acidophilus, Lactobacillus salivarius, Bifidobacterium lactis and Escherichia coli. Benef. Microbes 1, 283-295, https://doi.org/10.3920/BM2010.0003

Putaala H., Salusjärvi T., Nordström M., Saarinen M., Ouwehand A.C., Bech Hansen E., Rautonen N., 2008. Effect of four probiotic strains and Escherichia coli 0157:H7 on tight junction integrity and cyclo-oxygenase expression. Res. Microbiol. 159, 692-698, https://doi.org/10.1016/j.resmic.2008.08.002

Reichling J., Schnitzler P., Suschke U., Saller R., 2009. Essential oils of aromatic plants with antibacterial, antifungal, antiviral, and cytotoxic properties - an overview. Forsch. Komplementmed. 16, 79-90, https://doi.org/10.1159/000207196

Simmons D.L., Botting R.M., Hla T., 2004. Cyclooxygenase isozymes: the biology of prostaglandin synthesis and inhibition. Pharmacol. Rev. 56, 387-437, https://doi.org/10.1124/pr.56.3.3
Tiihonen K., Kettunen H., Bento M.H., Saarinen M., Lahtinen S., Ouwehand A.C., Schulze H., Rautonen N., 2010. The effect of feeding essential oils on broiler performance and gut microbiota. Br. Poult. Sci. 51, 381-392, https://doi.org/10.1080/ 00071668.2010 .496446

Ulluwishewa D., Anderson R.C., McNabb W.C., Moughan P.J., Wells J.M., Roy N.C., 2011. Regulation of tight junction permeability by intestinal bacteria and dietary components. J. Nutr. 141, 769-776, https://doi.org/10.3945/jn.110.135657

Veeriah S., Hofmann T., Glei M., Dietrich H., Will F., Schreier P., Knaup B., Pool-Zobel B.L., 2007. Apple polyphenols and products formed in the gut differently inhibit survival of human cell lines derived from colon adenoma (LT97) and carcinoma (HT29). J. Agric. Food Chem. 55, 2892-2900, https://doi. org/10.1021/jf063386r

Youn H.S., Lee J.K., Choi Y.J., Saitoh S.I., Miyake K., Hwang D.H., Lee J.Y., 2008. Cinnamaldehyde suppresses toll-like receptor 4 activation mediated through the inhibition of receptor oligomerization. Biochem. Pharmacol. 75, 494-502, https://doi. org/10.1016/j.bcp.2007.08.033

Yuan J.H., Dieter M.P., Bucher J.R., Jameson C.W., 1992. Toxicokinetics of cinnamaldehyde in F344 rats. Food Chem. Toxicol. 30, 997-1004, https://doi.org/10.1016/0278-6915(92)90109-X 